\title{
Processos de auto(trans)formação permanente com educadores: possibilidades de reinuenção da pedagogia popular na escola pública
}

\section{Self(trans)formation processes permanent with educators: possibilities of reinuention of the pedagogy of popular education in the public school}

\section{Procedimientos de auto(trans)formación permanente con educadores: posibilidades de reinuención de la pedagogía popular en la escuela pública}

\section{Celso Ilgo Henz'}

Universidade Federal de Santa Maria, Professor associado 4 e Pesquisador do PPGE, na Linha de Pesquisa: Formação, Saberes e Desenuolvimento Profissional

\section{Patrícia Signor $^{2}$}

Universidade Federal de Santa Maria, Professora da Educação Básica e Ensino Superior; Participante do grupo de estudos e pesquisas Dialogus: educação, formação e humanização com Paulo Freire, com registro no $\mathrm{CNPq}$

Resumo: Neste artigo apresentam-se reflexões de uma pesquisa qualitativa, fruto de uma dissertação de mestrado em que se propôs estudar e compreender a auto(trans)formação permanente de professores e estudantes pelo entrelaçamento da práxis educativa escolar com a pedagogia popular. Foram abordados os conceitos de formação permanente (FREIRE, 201 la), formação docente (IMBERNÓN, 2011 ) e auto(trans)formação permanente (HENZ; FREITAS, 2015a, 2015b). O trabalho traz as contribuições da pedagogia popular de Freire (201 la) como uma possibilidade para a escola pública e uma educação mais significativa para educandos e educadores. A abordagem metodológica escolhida foi embasada nos Círculos Dialógicos Investigativo-formativos (HENZ, 2014, 2015; HENZ; FREITAS, 2015a), que privilegiam espaços de diálogo e auto(trans)formação docente com ênfase e proximidade no cotidiano dos estudantes e da comunidade. A metodologia caracteriza-se como pesquisa-

Pós-doutor em Formação Permanente de Professores na Educação Popular pela Universidad de Sevilla; Doutor em Educação pela Universidade Federal do Rio Grande do Sul.

2 Mestre em Educação pela Universidade Federal de Santa Maria; Doutoranda em Educação pela Universidade Federal de Santa Maria. 
participante (BRANDÃO, 2001), realizada por meio de Círculos Dialógicos Investigativo-formativos com o coletivo de educadoras de uma escola pública de Barra Funda, RS. A análise mostrou que o diálogo tem muito a contribuir para os momentos de auto(trans)formação com as educadoras, coautoras da pesquisa, a partir de temáticas cotidianas e inquietantes que emergiram dos Círculos, abrindo a possibilidade de auto(trans)formação para que os docentes e a própria escola pública construam uma educação mais problematizadora, dialógica e humana.

Palavras-chave: Auto(trans)formação permanente. Educação popular. Escola pública.

Abstract: This article presents reflections of a qualitative research, the result of a master's thesis that aims to study and understand the permanent self(trans) formation of teachers and students through the interlacing of the educational practice praxis with the popular pedagogy. Were interlaced the concepts of permanent formation (FREIRE, 201 la), teacher training (IMBERNÓN, 2011) and permanent self(trans)formation (HENZ; FREITAS, 2015a, 2015b), the work brings the contributions of Freire's popular pedagogy (201 la) as a possibility for the public school and a more meaningful education for the learners and educators. The methodological approach chosen was based on the Investigative-Formative Dialogical Circles (HENZ, 2014, 2015; HENZ; FREITAS, 2015a), which privilege spaces for dialogue and self(trans)formation teacher with emphasis and closeness in the students, involved with the community and the reality of the subjects. The methodology is characterized as researchparticipant (BRANDÃO, 2001), performed by means of Investigative-formative Dialogical Circles with the collective of educators of a public school in Barra Funda, RS. The analysis showed that the dialogue has much to contribute to the moments of self(trans)formation of the educators, coauthors of the research, from the daily and disturbing themes that emerged from the Circles, opening the possibility of self(trans)formation for teachers and the public school itself can construct a more problematic, dialogical and human education.

Keywords: Self(trans)formation. Popular education. Public school.

Resumen: Este artículo presenta reflexiones de una investigación cualitativa, resultado de una tesis de maestría que se propuso a estudiar y comprender la auto(trans)formación permanente de profesores y estudiantes por el 
entrelazamiento de la praxis educativa escolar con la pedagogía popular. En este sentido, el trabajo trae las contribuciones de la pedagogía popular de Freire, y se ha conexo a los conceptos de formación permanente (FREIRE, 201la), formación docente (IMBERNÓN, 2011) y auto(trans)formación permanente (HENZ; FREITAS, 2015a, 2015b) como una posibilidad para la escuela pública y una educación más significativa para los educandos y educadores. El enfoque metodológico escogido se basó en los Círculos Dialógicos Investigativo-formativos (HENZ, 2014, 2015; HENZ; FREITAS, 2015a) que privilegian espacios de diálogo y auto (trans) formación docente con énfasis y proximidad en el cotidiano de los estudiantes y la comunidad. La metodología se caracteriza como investigación-participante (BRANDÃO, 2001), hecha por medio de Círculos Dialógicos Investigativo-formativos con el colectivo de educadoras de una escuela pública de Barra Funda, RS. El análisis mostró que el diálogo contribuye con los momentos de auto(trans)formación de las educadoras, coautoras de la investigación, a partir de temáticas cotidianas e inquietantes que surgieron de los Círculos, abriendo la posibilidad de auto (trans) formación para los docentes y la propia escuela pública construya una educación más problemática, dialógica y humana.

Palabras clave: Auto(trans)formación permanente. Educación popular. Escuela pública.

\section{PRIMEIRAS PALAURAS}

A educação pública precisa, a cada dia mais, de pessoas engajadas no árduo propósito de transformação em busca de qualidade social, ${ }^{3}$ garantindo o acesso e a permanência dos estudantes na escola, bem como a democratização do conhecimento e da gestão, para que realmente seja um direito e uma conquista de todos.

\footnotetext{
3 Na obra Professora, sim; tia, não!, Freire (1993, p. 44) conduz para a reflexão de que não há qualidades neutras, "educação e qualidade são sempre uma questão política, fora de cuja reflexão, de cuja compreensão não nos é possível entender nem uma nem outra." Importante, ao falar de qualidade e de educação ter a clareza da natureza política e social que esses termos assumem, sob a ótica da pedagogia popular. Os termos qualidade social ou qualidade socialmente referenciada vêm opor-se à ideia da qualidade total, defendida na ótica neoliberal e pelas políticas de valorização de mercado.
} 
Um importante passo dado no caminho para pensar a escola de modo mais humanizado é o reconhecimento da auto(trans)formação permanente como parte fundamental do trabalho do profissional em educação. Esse acontecimento proporciona ao professor maior reconhecimento ao seu quefazer de preparação e condução das aulas, e às escolas, maior autonomia e recursos para organizarem o trabalho em consonância com o coletivo de professores, indo ao encontro da construção e da consolidação da proposta ideológica de educação libertadora (FREIRE, 201 la, 2013) e da concepção de um mundo e uma sociedade mais justos, com condições de vida e cidadania para todos.

Privilegiar os espaços de participação e diálogo nas escolas é valorizar a capacidade e as vivências dos profissionais da educação - professores e funcionários - em nome de engajá-los como protagonistas da instituição e da comunidade da qual fazem parte, concebendo o diálogo como fundamental para a auto(trans)formação dos sujeitos e da realidade dos estudantes. É nessa ótica que se buscou, com a pesquisa, compreender quais as possibilidades da auto(trans)formação permanente com professores pelo entrelaçamento da práxis educativa escolar com a pedagogia da educação popular, estudando um contexto de escola pública de Educação Básica nos seus momentos de formação por meio dos Círculos Dialógicos Investigativo-formativos.

Partiu-se de um questionamento muito simples: é possível tornar a escola pública mais significativa para seus educandos? Por trás desse questionamento há a necessidade de ajudar o professor a encontrar o seu lugar como sujeito de ações, de responsabilidades e de muitas capacidades para com a escola e seus educandos.

Neste artigo apresentam-se apontamentos acerca da formação permanente enquanto articuladora da prática e geradora de experiências significativas aos docentes e, consequentemente, aos estudantes; e abordamse teorias acerca da formação docente sob a ótica da pedagogia de educação popular e das contribuições para os processos de auto(trans)formação que ocorrem na escola pública durante a formação com professores. Trazemse os Círculos Dialógicos Investigativo-formativos enquanto possibilidade de reinvenção do espaço escolar, por meio da auto(trans)formação com professores, tendo por base os movimentos da escuta sensível, do olhar 
aguçado, da descoberta do inacabamento, da emersão das temáticas, dos diálogos problematizadores e da conscientização, metodologia esta que se fundamenta em Freire (201 la, 2013) e Josso (2004) e vem sendo construída pelo grupo Dialogus, conforme indica Henz (2014, 2015).

Em seguida, apresenta-se a experiência dos Círculos Dialógicos em uma escola pública que estuda e ressignifica a educação popular no contexto da formação docente. Foram realizados seis momentos de auto(trans)formação utilizando a metodologia dos Círculos Dialógicos Investigativo-formativos; nesses encontros foram abordadas temáticas condizentes ao contexto escolar e problematizados avanços e possibilidades de (re)significar os contextos educativos, para professores e estudantes, a partir das contribuições dos próprios educadores. Fragmentos de falas das educadoras que aceitaram o desafio de construir um espaço de formação ousado, apontando fragilidades e potencialidades que a escola, como um todo, apresenta, constituem-se registros significativos no presente texto.

$\mathrm{Na}$ parte final deste escrito, que não foi chamada de conclusão em coerência à proposta político-epistemológica do trabalho, apresentam-se considerações acerca do que aconteceu na escola com a realização dos Círculos Dialógicos quanto aos processos de significação da prática docente sob a ótica da educação popular. Nessa parte, o estudo apresenta interpretações a respeito dos resultados da pesquisa, autoavaliações das coautoras (docentes da escola) e contribuições para o seguimento do processo de auto(trans)formação docente no viés do diálogo, da valorização dos saberes populares, do reconhecimento da inconclusão humana e da humildade pedagógica para reinventar constantemente as práticas educativas e o sentido de ser da escola pública. 


\section{A FORMAÇÃO PERMANENTE NA ESCOLA PÚBLICA: EXPERIÊNCIA GERADORA DE SENTIDOS AO COTIDIANO DO PROFESSOR}

Bem sabem os que vivem a docência que ela não se constitui uma tarefa simples, tampouco pode ser exercida sem plena consciência da intencionalidade com a qual se atuará em um contexto de interação com outras vidas.

Compreender a docência como espaço de aproximação com os educandos é se deixar estar com eles em uma relação de aprendizagem. 0 olhar ao e com o educando, como ser de consciência e que, com os demais fatores (condições de trabalho em grupo, materiais, salário, reconhecimento social, bem-estar, saúde e qualidade de vida), constitui um docente humano que desempenha plenamente sua profissão possibilita a formação de uma concepção humana e dialógica de aprendizagem, na qual se aprende ao ensinar e se ensina ao aprender. Ao admitir-se humano, este docente também se admite imperfeito, sem todas as respostas que gostaria e necessitaria dominar, porém, na concepção dialógica da educação, isso não diminui o educador, o coloca em plano de aprendizagem com seu educando. Se humano, logo, imperfeito, sem todas as respostas que gostaria e necessitaria dominar. Segundo Imbernón (2011), faz-se interessante analisar o que se considera profissionalismo e profissionalização em relação ao desempenho da profissão. Para ele, a profissionalidade constitui as "características e capacidades específicas da profissão [e a profissionalização, o] processo socializador de aquisição de tais características." (IMBERNÓN, 2011 , p. 25). Esses conceitos sociais e multidimensionais fundamentam-se em valores pessoais e são constituídos coletivamente, impulsionados em tempo e lugar históricos.

Por essa razão, afirma-se que o primeiro passo para que o professor possa se constituir é ter a consciência de que sua profissão não combina com conclusão. É importante, sim, saber por onde caminha e para onde pretende seguir, mas a conclusão de seus saberes e a constituição de sua professoralidade partem da premissa de que jamais deixará de se profissionalizar, de formarse por meio da reavaliação da sua prática, do conhecer seus educandos, de refletir acerca do seu fazer docente e de preocupar-se com o impacto de como 
a condução de suas práticas é capaz de interferir e de ajudar a constituir a identidade dos sujeitos. Como corrobora Freire (2011b, 2013), somente o profissional que é aberto à reflexão sobre suas práticas é capaz de desenvolver a autonomia e a participação dialógica com princípios de humanização, cidadania e democracia na escola e na sociedade.

Uma única certeza parece ser importante, a de que a docência se constitui uma profissão constantemente inacabada, e, com esse conceito, as implicações que a legitimam a caracterizam como um processo de continuidade, pelo contexto no qual é realizada e pelo produto ideológico da não neutralidade das concepções culturais, históricas e sociais do sujeito. Para Imbernón (201 1, p. 28), "o conceito de profissão não é neutro nem científico, mas é produto de um determinado conteúdo ideológico e contextual." Freire (201la, p. 122) afirma que o "saber igualmente fundamental à prática educativa do professor ou da professora é o que diz respeito à força, às vezes maior do que pensamentos, da ideologia." Segundo ele, a ideologia relacionase à "ocultação da verdade dos fatos", que nos torna míopes a ponto de não enxergarmos a realidade como ela ocorre.

Quando a docência se acredita imune à ideologia, passa a reproduzir concepções dominantes que reduzem as práticas educativas à mera transmissão de informações, sem que elas, verdadeiramente, sejam capazes de tornaremse significativas aos educandos. Freire (201la, p. 13l) afirma que, para se resguardar das artimanhas da ideologia, não é possível se fechar aos outros, nem acreditar que se é detentor da verdade. "Pelo contrário, o melhor caminho para guardar viva e desperta a minha capacidade de pensar certo, de ver com acuidade, de ouvir com respeito [...] é recusar posições dogmáticas, em que me admita como proprietário da verdade." Isso revela a postura dialógica que se espera do profissional docente: não um detentor de verdades, de conteúdos, de informações privilegiadas, mas um mediador de diálogos, de construções de aprendizagens, carregado de responsabilidades sociais intrínsecas ao processo de educação de si e do outro.

Para Imbernón (201 1, p. 28), reconhecer a docência e as atribuições de sua profissionalização não é assumir privilégios sobre os outros. Ao contrário, requer que, em seu exercício "o conhecimento específico do 
professor e da professora se ponha a serviço da mudança e da dignificação da pessoa", participando dos processos de emancipação econômica, política e social dos sujeitos, buscando contribuir para a percepção das opressões e manipulações existentes na sociedade, que esmagam e desumanizam homens e mulheres. É por carregar essas responsabilidades que o quefazer educativo de um professor perpassa o nível de formação e especialização em sua área de atuação. Esse trabalho necessita levar em conta o contexto escolar, os saberes que os educandos trazem consigo, a história da instituição e, principalmente, que tipo de educação se está disposto a realizar, que metodologia a escola se propõe a construir e como busca a concretização dessa proposta. Todos esses fatores devem ser considerados para o trabalho em sala de aula e pelos gestores no processo de organização e planejamento do trabalho docente. Poucos processos traduzem tão bem essa necessidade quanto a formação realizada na própria instituição.

A profissão professor implica uma consciência de estar sempre aprendendo, com os outros e com as situações; por isso, reconhecer a auto(trans)formação permanente como parte intrínseca dessa práxis educativa é um dos caminhos para torná-la mais significativa. Compreende-se que a formação faz sentido para o educador quando ele sabe que o espaço-tempo de "dar aula" é o mesmo no qual se aprende a fazê-la e no qual ele, enquanto profissional, constitui-se em agente de seu próprio fazer pedagógico. Por meio de permanentes processos de auto(trans)formação é que o educador reconstrói seu fazer pedagógico e sua concepção de educar.

Constituem saberes docentes quaisquer percepções, competências e habilidades que capacitem o indivíduo para a atividade profissional, sabendo que os docentes têm características distintas, heterogêneas e se conflitam constantemente durante a afirmação e constituição do profissional. Esses saberes característicos da profissão são constituídos pelos próprios docentes, com a participação do grupo do qual eles participam e dos contextos nos quais estão inseridos. Corrobora Tardif (2002) que são os saberes que os professores constroem em espaços de vida e de atuação; são saberes acionados nos espaços cotidianos de trabalho, muitos deles construídos no tempo-espaço de 
formação que não se limita ao espaço acadêmico, mas se desencadeia ainda em seu período de estudante.

Pensar transformações na trajetória da escola pública no Brasil também é reconhecer educadores, educandos e comunidade escolar nesses processos de constituição, reconhecimento e construção da escola enquanto instituição pública e democrática a serviço de interesses que, se não atendem, pelo menos deveriam atender às necessidades da maioria pobre e desassistida historicamente nos âmbitos social, cultural e econômico. Se o que se quer são bons resultados, não há melhor maneira de lutar pela qualidade social da educação senão juntos pelas mesmas causas. E pensar educação dessa maneira requer que se construam processos de formação capazes de propiciar ao educador a base teórica necessária para a realização de sua prática educativa. Freire (201 la) constrói seu conceito para a formação do educador sob o olhar democrático e suas implicações.

O educador democrático tem a dupla função de caminhar para sua completude como ser humano e como profissional, abrindo espaço para que o aluno também o faça, de modo que, se transformando (sic) individualmente, possa, também, fazê-lo coletivamente. A formação permanente do educador é, portanto, uma necessidade pedagógica e uma opção política. $\bigcirc$ professor tem direito à formação continuada, não apenas quanto a inovações tecnológicas, mas também quanto a sua atualização ampla e constante, que lhe proporcione uma visão cada vez mais ampla e profunda da realidade. (FREIRE, 201 la, p. 113).

Destaca-se, assim, a importância de refletir sobre a prática despertando uma "curiosidade ingênua" por meio do repensar das ações e do despertar da criticidade. Esse é um desafio permanente, que exige humildade e reconhecimento de sua condição humana, aprendendo/construindo um olhar mais solidário também aos e com os educandos, igualmente aos e com os colegas que fazem parte e auxiliam nos processos de ensino-aprendizagem como um todo e na concretização do trabalho de uma determinada instituição. $\bigcirc$ reconhecimento como profissional, a autoestima e a dedicação ao trabalho 
também são fatores que contribuem para a efetiva viabilidade e realização da inacabada auto(trans)formação permanente.

"A formação centrada nas situações problemáticas da instituição educativa através de processos de pesquisa significa realizar uma 'inovação a partir de dentro'" (IMBERNÓN, 201 1, p. 22), possibilitando pensar a escola pelos próprios rumos pedagógicos e sociais os quais direcionam sua formação. Ao docente, agrega-se o papel de pesquisador, não mais assujeitado, mas sujeito de sua própria auto(trans)formação. De dentro da instituição a qual pertence, o pesquisador é capaz de fazer de suas ações em sala de aula instrumentos para seu aperfeiçoamento e sua profissionalização, constituindose como um docente articulado à realidade e preocupado com questões sociais e pedagógicas.

\section{OS CÍRCULOS DIALÓGICOS INUESTIGATIUO-FORMATIUOS COMO AUTO(TRANS)FORMAÇÃO DO PROFESSOR E DO FAZER PEDAGÓGIICO}

Pensar o educador como sujeito de sua formação requer contemplar, durante o desenrolar da pesquisa, de que modo a auto(trans)formação permanente pode atuar como articuladora da realidade dos estudantes e do cotidiano dos professores. Considerando a auto(trans)formação permanente como condição para o trabalho educativo problematizador, dialógico e progressista, a investigação foi aprofundada no entrelaçamento da auto(trans)formação permanente dos professores na práxis educativa com um viés de transformações significativas aos estudantes e a sua realidade sociopolítica-econômica.

A busca por interação e contextualização da pesquisa, em virtude de uma concepção epistemológica humana e progressista, abre espaço para a realização dos Círculos Dialógicos Investigativo-formativos. É a presença e a propensão ao diálogo no questionamento, constatação e resolução dos fenômenos educacionais que envolvem a pedagogia da educação popular e a auto(trans)formação permanente de professores de uma escola pública. 
Grupo Dialogus vem consolidando os Círculos Dialógicos Investigativoformativos como alternativa para a auto(trans)formação permanente com professores, de maneira a propor uma escuta sensível e o diálogo aberto e problematizador acerca do próprio processo permanente de auto(trans) formação e das suas práxis educativas. Essa proposta político-epistemológica e metodológica mantém raízes nos Círculos de Cultura de Paulo Freire, articulados com os pressupostos da Pesquisa-formação ${ }^{4}$ de Josso (2004), com a valorização da dialogicidade, da escuta do outro e da construção da identidade, trabalhando com experiências de vida e formação que geram (re) significação e auto(trans)formação.

A significação dos movimentos circulares parte da ideia de Brandão (2001 ), que relaciona a simbologia do círculo à lembrança das experiências de cultura e de educação popular realizadas no Brasil e na América Latina a partir dos anos 1960. Para a educação popular, os círculos trazem uma potencialidade de transformações pessoais e sociais a partir de iniciativas comunitárias, escolares e pedagógicas. $\bigcirc$ círculo é uma crítica à educação bancária - em Freire (2013), a educação que silencia os educandos e educadores, que considera a sala de aula o único espaço de aprendizagem e o professor o único que pode deter e repassar o conhecimento - e propõe o posicionamento das pessoas em roda de conversa, na qual ninguém possui um lugar de destaque. O professor se torna uma espécie de mediador, o "coordenador de um diálogo entre pessoas a quem se propõe construírem juntas o saber solidário a partir do qual cada um ensina-e-aprende." (BRANDÃO, 2001, p. 69). A concepção dos círculos é proposta de igualdade de participação, autonomia, criticidade, consciência e solidariedade, conforme os eixos de transformações delimitados por Brandão (2001): - o de si mesmo como ser humano entre outros seres humanos em patamar de igualdade; - o das relações interativas em e entre grupos de pessoas empenhadas em ações, que sempre possuem um caráter

\footnotetext{
4 Trata-se de uma "experiência a ser elaborada para que quem nela estiver empenhado possa participar de uma reflexão teórica sobre a formação e os processos por meio dos quais ela se dá a conhecer." (JOSSO, 2004, p. 1 13). A pesquisa, com noção de processo, é o cenário da pesquisaformação e alimenta-se da observação de si mesma implicando aprendizagem e exercício de distanciamento, bem como a valorização dos saberes e das experiências dos participantes. Assim o cotidiano e a realidade deles tornam-se objeto de trabalho em sua singularidade.
} 
social e político indissociáveis ao objetivo de emancipação dos sujeitos por meio da criticidade das estruturas na vida social.

Já a pesquisa-formação, abordagem metodológica que fundamenta os Círculos Dialógicos Investigativo-formativos, consiste em uma "experiência a ser elaborada para que quem nela estiver empenhado possa participar de uma reflexão teórica sobre a formação e os processos por meio dos quais ela se dá a conhecer." (JOSSO, 2004, p. 113). A pesquisa com noção de processo é o cenário da pesquisa-formação e alimenta-se da observação de si mesmo, implicando aprendizagem e exercício de distanciamento; dessa forma, a valorização dos saberes e das experiências dos participantes e o seu cotidiano e realidade circunscrevente tornam-se objeto de trabalho em sua singularidade.

Para Henz e Freitas (2015a), a metodologia dos Círculos Dialógicos Investigativo-formativos, construída pelo Grupo Dialogus em suas atividades de encontros, formações em escolas públicas de Santa Maria e em seus projetos formativos, "possibilita a aproximação dialógica, permitindo voz e vez a cada interlocutor, bem como o repensar das práticas do grupo e de formação permanente." Essa relação foi sentida pelo coletivo da Escola Antônio João Zandoná, de Barra Funda, RS, que aceitou o desafio de participar e de compreender a potencialidade dos Círculos Dialógicos, à sua maneira, dando-lhes o seu contorno, mas sem perder os movimentos característicos da investigação, formação e diálogo já propostos nos Círculos de Cultura. Assim busca-se "reinventar" Freire, que em sua trajetória como educador, em um trabalho comum de conquista da linguagem, pressupondo o diálogo como condição essencial para sua realização, reunia-se com algumas pessoas do povo em Círculos de Cultura (FREIRE, 201 lb).

A ideia também é contemplada por Ghedin e Franco (201 1), quando colocam o cotidiano em destaque dentro da pesquisa qualitativa. Para eles, esse procedimento permite a compreensão do cotidiano e de vivências únicas repletas de sentido, com ênfase na intersubjetividade, na interpretação e na comunicação, tornando-o tempo-espaço para a imersão de possíveis transformações. Henz (2014, p. 3), ao abordar a metodologia dos Círculos Dialógicos Investigativo-formativos, também realça a compreensão de que o diálogo e a vivência cooperativa, dentro da auto(trans)formação permanente, 
possibilita "processos intersubjetivos e dialógicos pelos quais cada um vai se auto(trans)formando enquanto pessoa e enquanto profissional." Essa auto(trans) formação não é um processo individual, mas coletivo, um eu se auto(trans) forma no outro e com o outro, na mesma processualidade que potencializa e propicia a auto(trans)formação do outro. É no compartilhamento profundo do diálogo que o ser humano é capaz de se compreender e se transformar, a si e ao outro, desafiando ambos ao compromisso com a transformação da realidade. Ao participar dos Círculos, é desafio do mediador a percepção para além das palavras: cada gesto, cada ato, cada olhar e cada postura permitem interpretações possíveis entre os interlocutores.

Os Círculos Dialógicos, referidos neste artigo como metodologia da pesquisa de mestrado (SIGNOR, 2016), aconteceram durante reuniões semanais de "formação pedagógica", que estão sendo realizadas há mais de 10 anos pelas educadoras da escola, no entendimento de que a formação, o estudo e a reflexão acerca da prática pedagógica são elementos fundamentais para a manutenção da proposta pedagógica adotada, pelo viés da educação popular de Paulo Freire. Hoje, conforme previsto na Lei n. 11 .738/08, que garante jornada máxima de 2/3 (dois terços) das horas trabalhadas em interação com os educandos em sala da aula, consoante a LDB n. 9.394/96, as reuniões de formação fazem parte da carga horária dos educadores, compreendendo 1/3 (um terço) do tempo destinado à formação e aperfeiçoamento do tempo na escola.

Nesse trabalho, 20 educadoras foram coautoras e aceitaram, em decisão formalizada em ata de reunião de formação da escola, participar dos Círculos Dialógicos. Todas elas atuam em sala de aula, com estudantes do ensino fundamental e ensino médio; foram convidadas de modo geral todas as professoras da escola, pois se entende que é importante propiciar condições e oportunidades igualitárias, democráticas e efetivas para todas as educadoras, no intuito de promover diálogos amplos, contextualizados e pré-ocupados com a problematização da prática escolar cotidiana. Longe de ser uma prática espontaneísta, como afirma Brandão (2013 apud HENZ; FREITAS, 2015b), não se impõe sobre a realidade ou em cada caso; ela pode ser (re)criada para que melhor se aproxime e consiga privilegiar a realidade pesquisada. Isso se deve a essa metodologia não ser estanque, não ser rígida e fechada, 
sem descuidar de ser uma práxis rigorosa, problematizadora e dialógica. Por essa razão, para este artigo, são trazidas falas que compuseram os Círculos Dialógicos Investigativo-formativos e a interpretação delas a partir das teorias apresentadas ao longo do texto.

Henz e Freitas (2015b) apontam para alguns movimentos importantes de composição dos Círculos que foram construídos com o Grupo Dialogus no decorrer da concepção da metodologia, afirmando a dinâmica e a organização dos momentos. Para a realização dos Círculos, realizou-se uma conversa com as coautoras explicando o funcionamento da dinâmica e deixando clara a importância de sentirem-se à vontade para contribuírem nos diálogos a qualquer momento. Em um primeiro movimento ${ }^{5}$ pratica-se a escuta sensível e o olhar aguçado, pressupostos em Freire quando afirma que o diálogo somente ocorre na escuta e na observação do outro, e que esses movimentos transcendem a capacidade de falar, mas exigem o exercício de ouvir, de participar, de se relacionar. $\bigcirc$ diálogo que se inicia ao ouvir o outro e a si se relaciona à descoberta do inacabamento, "a progressiva consciência de que, como humanos, estamos em permanente processo de busca de auto(trans)formação." (HENZ; FREITAS, 2015b, p. 79). É na descoberta do inacabamento que nos tornamos empoderados a (re)pensar e (re)inventar a realidade e as práticas educativas cotidianas. Quando nos descobrimos e aceitamos a nossa incompletude, podemos passar para a problematização das questões que nos entravam, que é o movimento da emersão das temáticas, outro movimento que justifica a coautoria dos participantes dos Círculos, pois as temáticas tratadas emergem também do grupo, do cotidiano e da realidade; por isso, em cada vez que ocorrem, os Círculos adquirem singularidades. Essas temáticas são mobilizadas por meio de mais um movimento forte, os diálogosproblematizadores, dos quais partem as perguntas, indagações, discussões e provocações, por meio da ação-reflexão-ação. Na processualidade dialética

\footnotetext{
5 Por mais que tenham sido enumerados os movimentos previstos nos Círculos, de acordo com Henz e Freitas (2015b), isso não significa que eles ocorram de modo linear, nem que tenham a obrigatoriedade de emergir em todos os círculos de modo completo. É compreensível que em algum dos círculos transpareça mais um ou outro movimento. A ideia principal é que os coautores possam vivenciar uma experiência concreta de diálogo e compartilhamento ampliando as compreensões de mundo, de educação e contribuição como um todo para dar à prática educativa maior significação.
} 
em que os diferentes movimentos se entrelaçam e se implicam, constitui-se também o movimento da auto(trans)formação com as professoras coautoras da pesquisa, conceito que vem sendo discutido e fundamentado pelo Grupo Dialogus. Esse movimento acontece quando há a possibilidade de "vivenciar um processo dialógico de auto(trans)formação permanente, em que ambos (pesquisador e interlocutores) compartilham suas inquietações, desejos, esperanças, alegrias, frustrações, saberes, bem como problematizam suas experiências." (HENZ; FREITAS, 2015b, p. 79).

Ao se auto(trans)formarem os participantes podem também passar pelo movimento da conscientização, tomada de consciência do processo conduzido de alternativas para a ação concreta, a transformação de sua realidade, o que requer sempre também a transformação das suas práticas em todos os âmbitos e dimensões do seu sentir, pensar e agir (HENZ, 2003). "Cada um dos participantes vai tomando consciência das situações-limite que o circundam e começa a refletir criticamente sobre elas." (HENZ; FREITAS, 2015b, p. 80). É importante registrar que o decurso dos estudos do Grupo Dialogus tem apontado a criação de mais movimentos, a fim de contemplar as experiências vivenciadas pelos pesquisadores, professores e orientadores nos Círculos Dialógicos Investigativo-formativos. Por uma opção limitada pelo tempo e para não correr o risco de publicar informações ainda não rigorosamente discutidas e estudadas, optou-se por utilizar o número de movimentos, imagens e descrições construídas e vivenciadas até o presente momento, ressaltando que isso não reduz a compreensão holística dos processos que constituem e confiabilizam os Círculos Dialógicos como uma alternativa metodológica e epistemológica de compreender intrinsecamente o processo de auto(trans) formação permanente de educadores. ${ }^{6}$

\footnotetext{
6 Embora aqui se enfoque prioritariamente a auto(trans)formação com as professoras, entendemos que também ocorra a auto(trans)formação com os educandos, uma vez que as professoras estão implicadas nas reflexões e mudanças sobre suas práticas educativas.
} 
Figura 1 - Movimentos para a dinâmica dos Círculos Dialógicos Investigativo-formativos

\section{CÍRCULOS DIALÓGICOS INVESTIGA TIVO-FORMATIVOS}

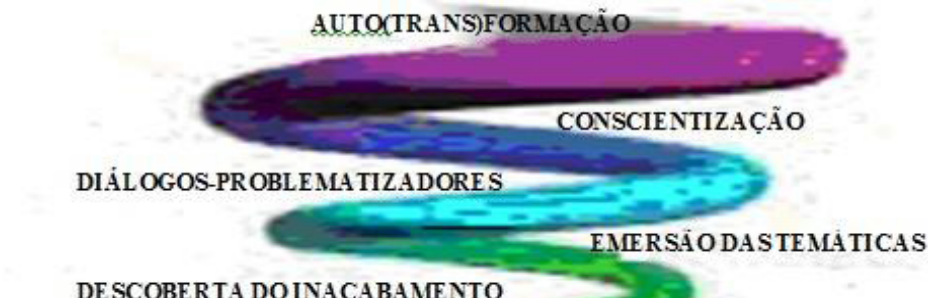

DESCOBERTA DOINACABAMENTO

\section{ESCUTA SENSIVEL/OLHAR AGUCCADO}

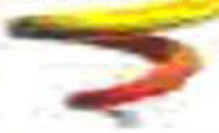

HENZ E FREITAS (2015)

Fonte: Henz e Freitas (2015b).

Contudo, por se tratar de uma metodologia que pressupõe diálogo, os movimentos não são estanques, tampouco ocorrem em ordem linear, podendo ser intercalados e se repetirem ao longo da realização dos Círculos, como embasa Josso (2004), considerando que a avaliação das motivações também orienta as escolhas, uma vez que é importante para o envolvimento e consolidação da identidade do grupo. Como já assinalado em Henz (2014), a auto(trans)formação com professores ocorre por meio de uma circularidade em espiral ascendente proativa que se movimenta dentro da condição ontológica do inacabamento humano em busca do "ser-mais".

Em relação à base da pesquisa qualitativa, escolheu-se como possibilidade metodológica a pesquisa participante como elemento de integração entre pesquisador e pesquisando à realidade de atuação desses sujeitos. Brandão (2001, p. 9-10) relaciona o conceito a um conhecimento coletivo, "a partir de um trabalho, que recria, de dentro para fora, formas concretas dessas gentes, grupos e classes participarem do direito e do poder 
de pensarem, produzirem e dirigirem os usos de seu saber a respeito de si próprias", bem como instrumento de empoderamento da participação e produção do saber popular, com finalidade social. "Participar da produção deste conhecimento e tomar posse dele. Aprender a escrever a sua história de classe. Aprender a reescrever a história através de sua história. Ter no agente que pesquisa uma espécie de agente que serve." (BRANDÃO, 2001, p. 11).

A pesquisa participante é aquela voltada para o povo, não realizada sobre, mas com os integrantes de um determinado contexto social, geralmente ligado a realidades excludentes e vulneráveis. É a realidade analisada e descoberta pelos que a vivem, sem "descolar" o contexto e as experiências, isolando-os em ambientes externos. A pesquisa da realidade nasce da necessidade de uma população discutir suas próprias problemáticas e palavras geradoras (termo usado por Freire), a fim de adquirir significação na construção da pesquisa em ciência.

A pesquisa participante, desse modo, constitui-se em uma ação engajada que convive, observa, reflete, pergunta e (re)constrói passagens, muito articulada com a pesquisa-formação e os Círculos Dialógicos. Tudo intrinsecamente ligado à reflexão constantemente dialógico-problematizadora, o que já no Círculo 1 realizado com as educadoras da escola Zandoná foi possível perceber. A educadora Utopia ${ }^{7}$ provoca reflexões acerca das problematizações dos professores e da resposta dos educandos.

Eu, às vezes, acho que eles [estudantes] falam o que queremos ouvir sim. Porque o que eles pensam desagrada e nós vamos rebater, sim, com certeza. Mas, na sala de aula, as minhas verdades não são as tuas verdades, depois eu vou me dar conta que eu estou defendendo algo que eu acredito, e o outro fala o que ele acredita que pra ela é verdade, e nós vamos ficar discutindo 30 dias, [...] e se constrói em cima do diálogo, mas não necessariamente nós vamos fazer todos pensarem da minha forma. (Utopia, Círculo 1, informação verbal).

\footnotetext{
7 Os nomes relativos às educadoras da escola são pseudônimos, escolhidos por elas mesmas, para serem identificadas durante a pesquisa.
} 
É perceptível na fala da educadora a valorização do diálogo, do impasse de opiniões e como o papel da mediação do educador é importante para a pesquisa e para a construção do saber por parte do estudante e também do professor. Em uma pesquisa participante e cooperativa, teremos, sem dúvida, o diálogo e a interação de opiniões e opções distintas, propiciando que assim se constitua a diversidade e o conhecimento pelo envolvimento cooperativo de todas. Esses movimentos de investigação auto(trans)formativa impulsionam para a ação, tornando a sala de aula um ambiente vivo, dinâmico e propulsor para transformações reais e significativas para os envolvidos naquela localidade, especialmente os estudantes.

Buscou-se entrelaçar os Círculos Dialógicos Investigativo-formativos por meio da compreensão da linguagem e, por consequência, do ser, do cotidiano e da pertinência sobre as temáticas emergentes dos diálogos. Essa relação pode ser fundamentada no que afirma Kronbauer (2014) ao referenciar a expressão "círculo da compreensão", de Gadamer, como o "movimento entre o intérprete e a tradição, do processo de contínua formação no qual também a tradição vai sendo instaurada, com a participação do intérprete." (KRONBAUER, 2014, p. 334-335). Por meio do diálogo ocorre a tomada de consciência do indivíduo sobre si e suas concepções e práticas, sempre com o outro, e novas possibilidades podem surgir para auxiliar na reflexão e na ação acerca das problematizações realizadas em grupo.

\section{A AUTO(TRANS)FORMAÇÃO PERMANENTE, A UALORIZAÇÃO DOS SABERES PEDAGÓGICOS E O COTIDIANO DO PROFESSOR}

Os estudos que reúnem educação, formação e humanização em Paulo Freire, do Grupo Dialogus, ${ }^{8}$ vêm promovendo problematizações acerca da formação permanente e da descoberta do inacabamento e conscientização do ser durante sua constituição profissional, cultural e social. Esse desafio tem chegado ao alcance da concepção de auto(trans)formação permanente.

8 Com registro na base do CNPq desde 2011. 
Inerente aos movimentos dos Círculos Dialógicos Investigativo-formativos, essa compreensão resgata a genteidade dos educadores e educadoras em seus encontros e (des)encontros ao longo de sua (trans)formação pela ação-reflexãoação em sua constituição profissional. Segundo Henz (2014), o grupo acredita que os processos da auto(trans)formação permanente passam, necessariamente, pelo questionamento e pela reflexão dialógica que abrange capacidades, saberes, atitudes, sensibilidades, valores e concepções individuais e do grupo. Assim, nos Círculos Dialógicos, os participantes são constantemente desafiados a se (re)descobrirem, (re)organizarem seus saberes e (re)fundamentarem a prática por meio de estudos teóricos e de compreensão da cotidianidade da escola e do contexto. Nesse sentido, corrobora o depoimento da professora Planeta (Círculo 6, informação verbal),

eu queria comentar que eles [os alunos] não querem saber se tu tem 50, 30 ou 40 anos e quando eu coloco as práticas. Eu acho que o ano passado foi um ano ímpar; a gente terminou e tinha alunos do $7^{\circ}$ ano que choravam porque tinha terminado o ano letivo. Isso é inédito! A gente tem que manter o nosso a mil porque eles vêm e não param... Então eu acho que tudo o que puderes fazer para cativá$\operatorname{los}[\ldots]$

O depoimento da docente é um fio de luz e esperança no movimento do inacabamento e da conscientização, por perceber que, mesmo depois de muitos anos de docência, ela revê sua profissão, preocupa-se em motivar e trazer os estudantes para si, para as aulas, para a escola. Assim, corrobora com a proposta de Freire que, quando trata da inconclusão, conduz também à permanente renovação da práxis e do esperançar na educação.

Os processos contínuos, sistemáticos, organizados e (auto)reflexivos que são construídos pelo indivíduo ingressante na formação inicial e na decisão da carreira, seguindo até o exercício continuado da docência, são o que Marcelo (1995) compreende por desenvolvimento profissional docente: "são esforços dos professores na dimensão pessoal e na interpessoal, bem como as condições oferecidas por suas instituições no intuito de criarem condições para que esse processo se efetive." (ISAIA; BOLZAN, 2009, p. 375). 
Englobam a concepção de conhecimentos, saberes e fazeres voltados para o exercício da profissão, que sofre influências dos contextos sociais, culturais, políticos e ideológicos pelos quais o professor se faz profissional. Além do que, "el desarrollo profesional se especifica como una actitud permanente de indagación, de planteamiento de cuestiones y la búsqueda de sus soluciones" (MARCELO, 1995), revelando um profissional que se engaja e participa da própria constituição profissional de si e do outro.

A postura dialógica esteve muito presente nos encontros dos Círculos Dialógicos com as professoras, com o intuito de olhar para a proposta da escola e, sobremaneira, para a sua prática. A professora Curiosidade, questionando - grupo de educadoras sobre como é possível trabalhar desconectado da realidade se esta envolve toda a vida, deu abertura para um momento de auto(trans)formação pela escuta sensível do capítulo 1.1 da obra Pedagogia da Autonomia Ensinar exige rigorosidade metódica; ali Freire (201 la, p. 28) ressalta "a importância do papel do educador, o mérito da paz com que viva a certeza de que faz parte de sua tarefa docente não apenas ensinar os conteúdos, mas também ensinar a pensar certo." Já a educadora Luz imediatamente questionou: "O que é o pensar certo?" E o grupo todo, ao silenciar diante de um questionamento complexo, foi interrompido pelas reflexões da professora Força com a seguinte análise:

o pensar certo mesmo que não esteja certo, ele já é certo, me parece que o pensar certo é o movimento, é o se envolver, o pensar, o agir não só o pensar. Porque ele [Freire] dá o exemplo dos livros... Não adianta ler 20, 30 livros e você não fazer nenhuma relação daquilo que está lendo com a realidade. Enfim, quando ele fala aí, "só, na verdade, quem pensa certo, mesmo que, às vezes pense errado, é quem pode ensinar a pensar certo" (FREIRE, 201 la, p. 29). Então eu acho que é o movimento, essa desacomodação, esse envolvimento. (Força, Círculo 1, informação verbal).

Ao perceber que ao educador é necessário esse movimento incessante de construção e reconstrução, há também a tomada de consciência do inacabamento da profissão e do ser humano, da necessidade de buscar, de tentar e de ousar 
que tanto traz Freire em suas reflexões acerca do papel do educador. A escuta dos demais e a preocupação da docente em questionar-se e problematizar a temática acena para o desejo de crescimento, de auto(trans)formação.

\subsection{O DIÁLOGO E A AUTO(TRANS)FORMAÇÃO COMO SIGNIFICAÇÃO DA FORMAÇÃO PERMANENTE NA PRÁTICA DOCENTE: CONSIDERAÇÕES ACERCA DA PESQUISA}

$\bigcirc$ estudo feito por meio dos Círculos Dialógicos Investigativoformativos encontrou um ambiente e pessoas abertas ao diálogo, dispostas a se mostrarem e a crescerem a partir dos momentos de formação. Longe da perfeição sequer almejada, ou de modelos a serem seguidos, a escola Zandoná reafirma sua opção problematizadora ao se permitir enxergar a formação permanente também como auto(trans)formação, proposta da presente pesquisa. Ao se descobrir em suas contradições, é perceptível que pelo menos parte das professoras compreende o viés da educação popular na metodologia da escola e procura mantê-lo vivo por meio de sua práxis, engajamento com a instituição e compromisso com a proposta.

A pedagogia de educação popular traduz-se no processo de formação docente pelos princípios do diálogo, da escuta sensível, da humildade pedagógica e do reconhecimento de que é preciso aprender sempre e permanentemente refletir e rever suas práticas. Há avanços percebidos na prática, como a tentativa de instituir a avaliação enquanto processo e com foco na identificação dos progressos dos estudantes e na organização da carga horária e da divisão dos tempos escolares por áreas do conhecimento. Há, também, a compreensão de que os momentos de formação docente podem ocorrer no ambiente escolar e que, dessa forma, podem contribuir de modo aprofundado para repensar ações voltadas às demandas da própria escola, ampliando-se o potencial (trans)formador das ações realizadas. Existe, entre o corpo docente, a crença e, ousa-se dizer pelas suas atitudes, a consciência 
de que é preciso repensar a educação pública e que há, entre educadores, o potencial para essa transformação.

\section{INTERROMPENDO, SEM CONCLUIR}

É preciso demarcar que no presente artigo, recorte da dissertação de mestrado (SIGNOR, 2016), trata-se da pedagogia de educação popular como possibilidade de transformação da escola pública, aqui trabalhada de modo mais direcionado no viés da auto(trans)formação docente; contudo, o processo em sua amplitude não se limita apenas a esse campo. Pensar uma escola pública à luz da pedagogia da educação popular é entender como agentes do processo os educandos, os educadores e a comunidade; isso implica reconhecer e valorizar os saberes culturais, sociais e históricos do contexto no qual a escola se constitui e compreender o viés ideológico, político e social para o qual se faz educação: ou para ou com as classes populares. Porém, enquanto artigo, as considerações que foram tecidas aqui se concentram nos potenciais auto(trans)formativos, provocados pelos Círculos Dialógicos Investigativo-formativos, realizados no processo de formação docente com as educadoras da escola.

Nos Círculos a escuta sensível propiciou momentos de tomada de consciência da auto(trans)formação que ocorre durante a prática docente. Pensar sobre os fatos e buscar trabalhar aliando-os à realidade trouxe às docentes, segundo seus próprios depoimentos, força e coragem para seguir adiante; afinal, é quando percebem que seu trabalho não está sendo em vão que as educadoras se consolidam como coletivo e fortalecem a proposta metodológica que a escola vem mantendo há mais de 10 anos: buscar o desenvolvimento de saberes, habilidades e relações com os conhecimentos historicamente acumulados e a realidade dos estudantes e da comunidade na qual é inserida. A valorização da educação pública e da formação docente com o viés popular, com vistas à humanização da educação, vê os educadores 
e educandos como sujeitos de seus próprios processos de construção de aprendizagens.

Ao estudar o conceito de auto(trans)formação, que transcende todos os momentos do presente estudo, foi possível compreender que o "auto" não é um auto sozinho, mas um auto de si, intersubjetivo e dialógico-reflexivo. Ou seja, ninguém se auto(trans)forma só; é preciso do coletivo, do outro, da interação e da dialogicidade. O trans é o além e o diferente possível, o algo a mais. Então, se a proposta inicial foi vislumbrar novas possibilidades para tornar a educação mais significativa para e com os educandos, por meio da formação de professores, precisava ir além da formação que já realizavam, e socializála com as demais colegas seria importante. Bem como a formação precisava contemplar temáticas que fossem emergentes de necessidades da própria escola. Para acontecer a auto(trans) durante a formação, também se sentiu necessário, por parte das educadoras, despir-se de orgulho e do ego para falar de si, de sua prática, direcionar um novo olhar para os conhecimentos, para a realidade; e isso nem todas estão/estavam preparadas e dispostas a fazer. É uma tarefa difícil assumir erros, reconhecer falhas e dispor-se a transformá-las.

A metodologia dos Círculos Dialógicos ampliou o tempo-espaço para o debate reflexivo e problematizador, configurando-se em momentos de estudos, nos quais as educadoras tiveram a possibilidade de dialogar de modo aberto, sincero e rigoroso, observando os movimentos dos Círculos, a fim de ampliar as discussões acerca de uma escola pública mais significativa e comprometida com a transformação da realidade dos estudantes, princípios esses da pedagogia da educação popular (FREIRE, 201 la).

Os processos de auto(trans)formação por meio dos Círculos Dialógicos Investigativo-formativos não foram momentos "descolados" da proposta da escola, como lembra a educadora Transformação na autoavaliação feita com o grupo; para ela, os Círculos reforçaram a ideia do quão necessários são o diálogo e a construção coletiva, "mais exigente me diz e o olhar acerca da minha práxis transformou-se em possibilidade de vir a ser, ou seja, alimento para minha tarefa de educar. Procuro sempre participar, externalizar o que sei e o que não sei como algo inacabado." Também para a educadora Lua, "a proposta conseguiu 'extrair' as ideias dos professores, já que esses não se 
sentem 'amedrontados', 'entrevistados', já que a sistemática do diálogo é o diálogo em grupo." Para a educadora Fé, a metodologia ajudou a "clarear a proposta da escola e foi de fundamental ajuda para as professoras que começaram a vida docente na escola, com o 'trem andando'" (informações verbais), fazendo-a repensar na prática educativa.

Ficam, aqui, poucas certezas e muitas perguntas. Poucas conclusões, mas muitas reflexões. Fica o legado da pesquisa, do registro e o compromisso de tornar possível uma educação humanizadora, dialógica e que possa contribuir para uma auto(trans)formação com educadoras e educandos que levem adiante o brilho nos olhos e a utopia compromissada de transformar seus mundos e suas próprias histórias e vidas.

Uma escola que não tem esperança é uma escola morta. A esperança, do verbo esperançar, não a do verbo esperar, como lembra Freire, aquela que acredita em uma utopia possível, em sonhos alcançáveis e em um trabalho árduo, mas importante a se realizar: transformar a educação pública neste País. É muito difícil fazer os encaminhamentos finais ao trabalho quando ainda resta tanto a saber, a buscar e a dizer, faz-se, então, um fechamento - quiçá temporário - com algumas palavras das coautoras a respeito da escola, da educação e de suas práticas.

Esperança - profetismo é muito importante denúncia e anúncio, o país que temos e o país que queremos: os desafios e as possibilidades.

Planeta - não podemos perder a esperança!

Amizade - nós não podemos perder a esperança e também nós não podemos desistir dos alunos! (Círculo 6 , informações verbais).

\section{REFERÊNCIAS}

BRANDÃO, C. R. Pesquisa Participante. 8. ed. 2. reimp. São Paulo: Brasiliense, 2001.

FREIRE, P. Professora sim, tia não: Cartas a quem ousa ensinar. São Paulo: Olho D'água, 1993. 
FREIRE, P. Pedagogia da autonomia: saberes necessários à prática educativa. 43. ed. São Paulo: Paz e Terra, 201 la.

FREIRE, P. Pedagogia da esperança: um reencontro com a pedagogia do oprimido. 17. ed. São Paulo: Paz e Terra, 2011 b.

FREIRE, P. Pedagogia do oprimido. 55. ed. Rio de Janeiro: Paz e Terra, 2013.

GHEDIN, E.; FRANCO, M. A. S. Questões de método na construção da pesquisa em educação. 2. ed. São Paulo: Cortez, 2011.

HENZ, C. I. Círculos Dialógicos Investigativo-formativos e Auto(Trans)Formação Permanente de Professores. In: HENZ, C. I.; TONIOLO, J. M. S. A (Org.). Dialogus: círculos dialógicos, humanização e auto(trans)formação de professores. São Leopoldo: Oikos, 2015.

HENZ, C. I. "Círculos Dialógicos Investigativo-formativos": pesquisa-formação permanente de professores. In: SEMINÁRIO NACIONAL: DIÁLOGOS COM PAULO FREIRE - POR UMA PEDAGOGIA DOS HUMANOS, 8., 2014, Bento Gonçalves. Anais... Bento Gonçalves: Ed. URI, 2014.

HENZ, C. I.; FREITAS, L. M. Círculos Dialógicos Investigativo-formativos: uma possibilidade de pesquisa entrelaçando os Círculos de Cultura freireanos com a pesquisa-formação. In: FÓRUM DE ESTUDOS: LEITURAS DE PAULO FREIRE - EDUCAR COM SERIEDADE SIM, MAS COM ALEGRIA! AS CLASSES POPULARES NA ESCOLA PÚBLICA, 17., 2015, Santa Maria. Anais... Santa Maria: Ed. UFSM, 2015a.

HENZ, C. I.; FREITAS, L. M. Círculos Dialógicos Investigativo-formativos: uma proposta epistemológico-política de pesquisa. In: HENZ, C. I.; TONIOLO, J. M. S. A. (Org.). Dialogus: círculos dialógicos, humanização e auto(trans)formação de professores. São Leopoldo: Oikos, 2015b.

HENZ, C. I. Razão-emoção Crítico-reflexiva: um desafio permanente na capacitação de professores. Tese (Doutorado em Educação)-Universidade Federal do Rio Grande do Sul, Porto Alegre, 2003.

IMBERNÓN, F. Formação docente e profissional: formar-se para a mudança e a incerteza. 9. ed. São Paulo: Cortez: 2011.

ISAIA, S. M. A.; BOLZAN, D. P. V. Trajetórias da docência: articulando estudos sobre processos formativos e de aprendizagem de ser professor. In: ISAIA, S. M. A.; BOLZAN, D. P. V. (Org.). Pedagogia Universitária e desenvolvimento profissional docente. Porto Alegre: EDIPUCRS, 2009. 
JOSSO, M. C. Experiências de vida e formação. São Paulo: Cortez, 2004.

KRONBAUER, L. G. Gadamer: hermenêutica filosófica e educação. In:

MARTINS, M. F; PEREIRA, A. R. (Org.). Filosofia e Educação: Ensaios sobre autores clássicos. São Paulo: EdUFScar, 2014.

MARCELO, C. Formación del professorado para el cambio educativo. 2. ed. Barcelona: EUB, 1995.

SIGNOR, P. A auto(trans)formação permanente e a pedagogia de educação popular: entrelaçamentos possíveis entre a práxis educativa escolar e a realidade dos estudantes. 2016. Dissertação (Mestrado em Educação)-Universidade Federal de Santa Maria, Santa Maria, 2016.

TARDIF, M. Saberes Docentes e Formação Profissional. Petrópolis: Vozes, 2002.

Recebido em 30 de janeiro de 2018 Aceito em 09 de julho de 2018

Endereços para correspondência: Universidade Federal de Santa Maria, Centro de Educação, Departamento de Administração Escolar, Faixa de Camobi, km 9, Campus Universitário Camobi, Centro, 97 105-900, Santa Maria, Rio Grande do Sul, Brasil; celsoufsm@gmail.com 